\title{
ARTIGOS
}

Recebido em 18.06.2013. Aprovado em 17.03.2014

Este artigo tem coautoria de membro do Corpo Editorial Científico da RAE, foi avaliado em double blind review, com isenção e independência

Editor Científico: Antonio Moreira de Carvalho Neto

DOI: http://dx.doi.org/10.1590/So034-759020150207

\section{ELEMENTOS PARA DISCUSSÃO DA ESCRAVIDÃO CONTEMPORÂNEA COMO PRÁTICA DE GESTÃO}

\author{
Elements for discussion of modern slave labor as a Management practice \\ Elementos para la discusión de la esclavitud contemporánea como práctica de gestión
}

\section{RESUMO}

O trabalho escravo contemporâneo está inserido nas relações de mercado entre organizações globais e seus fornecedores, e envolve práticas de gestão de pessoas que ferem os direitos humanos, como o cerceamento da liberdade, as condições degradantes de trabalho e a jornada exaustiva. 0 artigo analisa o trabalho escravo no Brasil e provê sustentação empírica para uma teoria da escravidão contemporânea como prática de gestão. Dois aspectos principais justificam esta contribuição. Em primeiro lugar, o debate chama a atenção à dinâmica da responsabilidade social e ao impacto das atividades empresariais nos países emergentes. Em segundo, põe-se em evidência a discussão do contexto da pobreza e suas inter-relações com o sistema de produção-consumo. 0 artigo sugere que 0 campo da Administração não detém a compreensão dos fundamentos da pobreza e de como práticas de gestão estariam implicadas na sua reprodução e no seu alívio. A agenda de pesquisa enfatiza a insustentabilidade de aspectos da globalização da produção e do consumo, e prioriza o problema.

PALAVRAS-CHAVE | Trabalho escravo, Brasil, escravidão contemporânea, relações de trabalho, sustentabilidade.

\section{ABSTRACT}

Contemporary slavery is embedded in market relations between global organizations and their suppliers, and involves people management practices that injure human rights such as curtailing freedom, degrading conditions of work and exhausting journey. The article analyzes the slave labor in Brazil and provides empirical support for a theory of contemporary slavery as a practice management. Two main aspects justify this contribution. First, the debate draws attention to the dynamics of social responsibility and the social impact of business activities in emerging countries. Secondly, it puts in evidence the discussion of poverty and its interrelations with the global system of production and consumption. The paper suggests that the field does not have the understanding of the fundamentals of poverty and how management is implicated in its reproduction and relief. The research agenda emphasizes the unsustainability aspects of the globalized production and consumption, and prioritizes the problem.

ANDRÉ OFENHEJM MASCARENHAS andre@zetesis.net

Sócio-fundador e pesquisador,

Zetesis - São Paulo - SP, Brasil

SYLMARA LOPES GONÇALVES DIAS sgdias@usp.br

Professora da Universidade de São Paulo, Escola de Artes, Ciências e

Humanidades - São Paulo - SP, Brasil.

\section{RODRIGO MARTINS BAPTISTA}

rodrigo2w2@hotmail.com

Professor da Universidade Anhembi

Morumbi, Política de Comércio

Exterior - São Paulo - SP, Brasil
KEYWORDS / Slave labor, Brazil, contemporary slavery, labor relations, sustainability.

\section{RESUMEN}

El trabajo esclavo contemporáneo está inserido en las relaciones de mercado entre organizaciones globales y sus proveedores, y envuelve prácticas de gestión de personas que hieren los derechos humanos, como el cercenamiento de la libertad, las condiciones degradantes de trabajo y la jornada exhaustiva. El artículo analiza el trabajo esclavo en Brasil y provee sustentación empírica para una teoría de la esclavitud contemporánea como práctica de gestión. Dos aspectos principales justifican esa contribución. En primer lugar, el debate llama la atención a la dinámica de la responsabilidad social y al impacto de las actividades empresariales en los países emergentes. En segundo, se pone en evidencia la discusión del contexto de la pobreza y sus interrelaciones con el sistema de producciónconsumo. El artículo sugiere que el campo de la Administración no detiene la comprensión de los fundamentos de la pobreza y de cómo las prácticas de gestión estarían implicadas en su reproducción y en su alivio. La agenda de pesquisa enfatiza la insostenibilidad de aspectos de la globalización de la producción del consumo, y prioriza el problema.

PALABRAS CLAVE / Trabajo esclavo, Brasil, esclavitud contemporánea, relaciones laborales, sostenibilidad. 


\section{INTRODUÇÃO}

A escravidão persiste em escala global na forma de relações desumanizadoras de trabalho, em exploração sexual e econômica. Quanto à exploração econômica, diversas formas de coerção caracterizam relações de trabalho no mercado formado por empresas globais, locais e suas cadeias de fornecedores, alijando trabalhadores de sua dignidade, ferindo seus direitos humanos. Segundo a Organização Internacional do Trabalho (OIT, 2009), a escravidão contemporânea é parte da economia mundial e sustenta a produção de uma gama de produtos.

A problemática revela aspectos nefastos da globalização da produção e do consumo, até agora pouco considerados pela prática e pela pesquisa em Administração. Isso porque, por um lado, poucas empresas, governos ou organizações não governamentais (ONGs) se engajam ou reconhecem o problema, entendendo que o trabalho escravo não seria central, mas periférico, sintomático, ou mesmo entendido como metáfora (Bales, 2004; Sakamoto, 2008). Por outro, o debate também é marginal nas ciências sociais (Bales, 2004), sendo praticamente ignorado no campo da Administração de Empresas (Cooke, 2003; Crane, 2013).

Este artigo discute elementos para uma teoria da escravidão contemporânea como prática de gestão (Crane, 2013), considerando o contexto brasileiro. Apesar de os dados revelarem uma realidade de grave violação aos direitos humanos, o Brasil está entre os poucos países que adotaram uma política de combate ao problema, que tem se tornado referência mundial, segundo a OIT (Bales, 2011; OIT, 2004). Foram 45.115 trabalhadores resgatados entre 1995 e 2013 (Procuradoria-Geral da União, 2014; Zocchio, 2013).

A análise do caso brasileiro busca dar sustentação empírica às proposições sobre as condições do macrocontexto institucional da escravidão. Para entender a escravidão contemporânea pelo ângulo da Administração, é essencial compreender como as empresas utilizam práticas ilegítimas para diminuir custos, sendo bem-sucedidas (Crane, 2013). Dois aspectos principais justificam esta contribuição.

Em primeiro lugar, o debate sobre o trabalho escravo contemporâneo chama a atenção à dinâmica da responsabilidade social e ao impacto das atividades empresariais nos países emergentes e na periferia do capitalismo (Blowfield \& Frynas 2005; Egri \& Ralston 2008; Idemudia 2011), revelando um conjunto de medidas e mecanismos de regulação pública e privada para solução das mazelas sociais (Bartley, 2007; Cashore, 2002; Crane \& Matten, 2010; Valente \& Crane, 2010).

Em segundo, evidencia o contexto da pobreza nas inter-relações que acontecem no cerne do atual sistema de produção-consumo em massa (Banerjee, Chio, \& Mir, 2009; Lindsay, 2010;
Thornley, Jeffreys, \& Appay, 2010). 0 artigo sugere que o campo da Administração não detém a compreensão dos fundamentos da pobreza e de como práticas de gestão estariam implicadas na sua reprodução e no seu alívio. Tais aspectos ficam frequentemente obscurecidos no debate (Crane, 2013; Lindsay, 2010; Singer, 2006;). A contribuição do artigo ao campo da Administração desdobra-se em uma agenda de pesquisa que enfatiza a insustentabilidade desses processos e prioriza o problema, indicando caminhos futuros para desenvolvimento da temática.

\section{TRABALHO ESCRAVO CONTEMPORÂNEO}

A escravidão reflete a vulnerabilidade social, a escassez de oportunidades, a pobreza crônica, o analfabetismo, o isolamento e a corrupção (Bales, 2007; Breton, 2002; Silva, 2004). Formas contemporâneas de escravidão incluem o trabalho forçado, a escravidão por posse, por dívida e o contrato de escravidão (Bales, Trodd, \& Williamson, 2009). Bales e Robbins (2001) propõem três elementos centrais ao conceito de trabalho escravo contemporâneo: o controle de um indivíduo sobre outro, a apropriação de força de trabalho e a imposição dessas condições pela violência ou ameaça. Apesar da ausência de uma definição universalmente aceita, mesmo no campo legal, os entendimentos sobre a escravidão contemporânea envolvem graus de variabilidade que podem ser entendidos num contínuo multifacetado desses elementos (Quirk, 2006).

A definição de escravidão é em si controversa (Quirk, 2006). Isso diz respeito não apenas aos diferentes entendimentos de que tipo de prática se constitui trabalho escravo, mas por que a inclusão de práticas específicas sob a rubrica sensível e politica de "escravidão" deve ser acompanhada de obrigações do estado e dos outros atores para tratar do problema (Crane, 2013). No Brasil, a política pública refere-se claramente ao "trabalho escravo", embora a maioria dos documentos mencione o termo "trabalho em condições análogas à escravidão" (Ministério do Trabalho e Emprego [MTE], 2011a). Diante dos acordos internacionais, a legislação brasileira é considerada avançada na tipificação do trabalho escravo. A partir de sua edição, em 2003, o artigo 149 do Código Penal Brasileiro definiu o crime de reduzir alguém "à condição análoga à de escravo" identificando quatro condutas que, em conjunto ou isoladas, caracterizam o crime: i) submeter o trabalhador a trabalho forçado; ii) a jornada exaustiva; iii) a condições degradantes de trabalho; e iv) restringir sua locomoção (MTE, 2011a).

Segundo Viana (2007), o termo condições degradantes enfatiza o poder extremo exercido pelo empregador, que impõe condições desumanizadoras de trabalho. A jornada exaustiva diz 
respeito ao trabalho que beira ou excede aos limites físicos do indivíduo. Para o MTE (2011b), seria considerado análogo à escravidão qualquer trabalho que cerceie a liberdade ou avilte a dignidade do trabalhador por meio de condições degradantes, mesmo quando não houver sua consciência dessa condição.

\section{POR UMA TEORIA DA ESCRAVIDÃO CONTEMPORÂNEA COMO PRÁTICA DE GESTÃO}

Crane (2013) delineia uma teoria da escravidão contemporânea como prática de gestão fundamentada na teoria institucional e na literatura sobre capacidades estratégicas. Suas proposições erguem-se a partir de insights de literaturas diversas, como a economia do crime, a economia informal, o tráfico humano e a análise legal e empírica da escravidão contemporânea. Crane (2013) discute (1) como as empresas exploram cenários competitivos e institucionais particulares que permitem a emergência da escravidão; (2) como se protegem de pressões institucionais contra a escravidão; e (3) como sustentam e moldam esses cenários que permitem ou previnem o florescimento da escravidão. Suas proposições consideram as condições do macrocontexto institucional que permitem à escravidão persistir e as capacidades no microcontexto de gestão necessárias a prosperar nessas condições. No Quadro 1, pode-se ver uma síntese da teoria formulada por Crane (2013).

\section{Metodologia de Pesquisa}

A problemática que norteou o levantamento empírico foi: Como tem acontecido o processo de construção e implantação da Política Nacional para Erradicação do Trabalho Escravo no Brasil (PNETE)? Por meio de uma estratégia qualitativa, desenvolveu-se um desenho de pesquisa que estabeleceu categorias teóricas para a análise do contexto brasileiro à luz da teoria da escravidão contemporânea como prática de gestão proposta por Crane (2013).

Quanto ao levantamento dos dados, adotaram-se procedimentos de seleção dos entrevistados, documentos e observação do tipo proposital. Participou-se de três seminários sobre o tema, em São Paulo e em Brasília, totalizando 26 palestras registradas, além de 12 entrevistas com acadêmicos, profissionais de ONGs, funcionários públicos e representantes de empresas. Esse percurso beneficiou-se do relacionamento dos pesquisadores com a equipe da ONG Repórter Brasil, que acompanhou a pesquisa fazendo leituras críticas de versões dos textos, parti- cipação em banca de mestrado, indicações e sugestões ao longo do levantamento. Foram reunidos dados primários (diário de observações, entrevistas semiestruturadas, registros em foto e vídeo) e secundários (diversos documentos e relatórios). Os dados foram analisados por meio de uma técnica de análise de conteúdo. Ao longo do processo analítico, foram utilizadas múltiplas fontes de evidências, apoio de especialistas para a leitura crítica das versões e triangulação de técnicas qualitativas com o apoio de software para organizar e categorizar os dados em torno das categorias empíricas e teóricas. Com apoio do software NVivo 9, atribuíram-se aos dados primários e secundários categorias gerais que foram, então, relacionadas às categorias teóricas propostas por Crane (2013).

Ao longo do levantamento e análise dos dados, optou-se por entender com maior profundidade os mecanismos regulatórios e instrumentos institucionais da política, os obstáculos técnicos e legais, os conflitos e a cooperação na institucionalização da política. Em termos de procedimentos de pesquisa, isso se traduziu em opções específicas para a definição das unidades de análise pertinentes, em função de como o fenômeno se revelava. Segundo a abordagem multicêntrica adotada, uma pluralidade de atores protagoniza o enfrentamento dos problemas públicos, tais como organizações privadas, ONGs, organismos multilaterais, juntamente com atores estatais, no estabelecimento das políticas públicas. Foi necessário, então, distinguir grupos de atores institucionais interligados em torno da problemática: (i) o poder público; (ii) a sociedade civil organizada; (iii) a iniciativa privada. Para aumentar o rigor dessa estratégia, analisou-se a finalidade de incorporar cada unidade de análise e identificaram-se os principais propósitos de estudá-las.

\section{ESCRAVIDÃO CONTEMPORÂNEA COMO PRÁTICA DE GESTÃO - EVIDÊNCIAS DO BRASIL}

A análise da problemática no Brasil dá sustentação empírica às cinco proposições de Crane (2013) sobre as condições do macrocontexto institucional da escravidão (as duas proposições sobre as capacidades de gestão necessárias a prosperar nessas condições não são escopo desta análise). Os fatores externos que moderam a incidência da escravidão podem ser classificados como condições relacionadas ao setor e ao contexto institucional, abrangendo sistemas regulatórios, normativos e culturais, e fatores políticos, socioeconômicos e geográficos (Crane, 2013, p. 13). 


\section{Quadro 1. Definição de categorias e proposições da teoria do trabalho escravo contemporâneo}

\begin{tabular}{|c|c|c|c|c|}
\hline Contexto & $\begin{array}{l}\text { Categorias de } \\
\text { análise }\end{array}$ & Descrição & Proposições geradas & \begin{tabular}{|l|} 
Variável \\
moderadora
\end{tabular} \\
\hline \multirow{3}{*}{$\begin{array}{l}\text { Macrocontexto } \\
\text { institucional }\end{array}$} & $\begin{array}{l}\text { Contexto } \\
\text { industrial }\end{array}$ & $\begin{array}{l}\text { Intensidade do uso de mão } \\
\text { de obra, valor distribuído ao } \\
\text { longo da cadeia produtiva, } \\
\text { elasticidade da demanda, } \\
\text { legitimidade e polos regionais. }\end{array}$ & $\begin{array}{l}\text { Proposição 1. A incidência da escravidão } \\
\text { contemporânea se concentra em setores com } \\
\text { mão de obra intensiva e não especializada, } \\
\text { que capturam pouco valor na cadeia produtiva } \\
\text { e enfrentam problemas de legitimidade; } \\
\text { incentivará a adoção do trabalho escravo pelos } \\
\text { empreendimentos. }\end{array}$ & $\begin{array}{l}\text { Proposição } 1 a \text {. } \\
\text { Efeitos podem ser } \\
\text { moderados pela } \\
\text { intervenção ao } \\
\text { longo da cadeia } \\
\text { produtiva. }\end{array}$ \\
\hline & Contexto cultural & $\begin{array}{l}\text { Tradição e crenças } \\
\text { religiosas entrelaçadas com } \\
\text { desigualdades sociais. }\end{array}$ & $\begin{array}{l}\text { Proposição 4. Um contexto cultural que reforça } \\
\text { desigualdades e naturaliza relações de trabalho } \\
\text { coercitivas incentivará a adoção do trabalho } \\
\text { escravo pelos empreendimentos. }\end{array}$ & \\
\hline & $\begin{array}{l}\text { Contexto } \\
\text { regulatório }\end{array}$ & $\begin{array}{l}\text { Governo e iniciativa privada } \\
\text { demonstram fraca governança } \\
\text { e pouca atenção em relação às } \\
\text { questões da escravidão. }\end{array}$ & $\begin{array}{l}\text { Proposição } 5 \text {. A existência e eficiência do contexto } \\
\text { regulatório impõe sanções à exploração de mão } \\
\text { de obra em condições análogas à escravidão; } \\
\text { incentivarão a adoção do trabalho escravo pelos } \\
\text { empreendimentos. }\end{array}$ & $\begin{array}{l}\text { Proposição } 5 \text { a. } \\
\text { Esse efeito pode } \\
\text { ser moderado pelo } \\
\text { desenvolvimento de } \\
\text { regulação privada e } \\
\text { pública. }\end{array}$ \\
\hline $\begin{array}{l}\text { Microcontexto } \\
\text { de habilidades } \\
\text { de gestão para a } \\
\text { escravidão }\end{array}$ & $\begin{array}{l}\text { Capacidade } \\
\text { para sustentar e } \\
\text { compartilhar }\end{array}$ & $\begin{array}{l}\text { Legitimação moral: aceitação } \\
\text { mínima do campo institucional } \\
\text { em torno da organização, } \\
\text { incluindo empregados não } \\
\text { escravos, trabalhadores } \\
\text { escravizados, clientes e } \\
\text { comunidade local, por meio de } \\
\text { comunicação persuasiva que } \\
\text { legitime, socialize essa cultura } \\
\text { organizacional } \\
\text { Manutenção do domínio: } \\
\text { operadores da escravidão } \\
\text { empregam métodos ilegais } \\
\text { para legitimar suas atividades } \\
\text { e dividir os riscos com atores } \\
\text { fora do mercado. }\end{array}$ & $\begin{array}{l}\text { Proposição } 7 \text {. A capacidade para sustentar e } \\
\text { compartilhar a cultura organizacional para a } \\
\text { escravidão media a relação entre as condições } \\
\text { externas e a adoção de práticas de escravidão. }\end{array}$ & \\
\hline
\end{tabular}


Quanto à primeira proposição, o contexto brasileiro corrobora a afirmação de que a escravidão contemporânea tende a florescer em setores que capturam pouco valor na cadeia produtiva e enfrentam problemas de legitimidade, apesar de o problema não estar restrito a esses setores. No Brasil, o ciclo do trabalho escravo geralmente acontece no início da cadeia de valor, que requer força física sem especialização. Sua incidência se concentra em setores com mão de obra intensiva e não especializada, como agricultura (cana-de-açúcar, grãos, algodão, erva-mate, pinus), pecuária, construção, vestuário e têxtil, carvão e corte de árvores (OIT, 2011). Existem muitos casos nos centros urbanos, mas o crime concentra-se em regiões rurais, especialmente em áreas de expansão agropecuária da Amazônia e do Cerrado, em fazendas que grilam, desmatam e queimam a floresta para a produção pecuária para o mercado doméstico e internacional, compreendendo quase 50\% dos casos autuados em 2013 (ver Tabela 1).
Mesmo considerando o grande número de autuações nas atividades predominantemente rurais, em 2013, chama atenção, na Tabela 1, que o número de trabalhadores envolvidos na construção civil foi superior ao da pecuária; certamente houve maior atenção e empenho dos órgãos fiscalizadores para as atividades desse setor. Outro exemplo seria o modelo do setor siderúrgico (apropriação de terras por um preço simbólico ou gratuito, baixa remuneração do trabalhador, isenções tributárias e ausência de investimento nas comunidades locais), que favoreceria condições degradantes de trabalho (Instituto Observatório Social [IOS], 2004). No setor de cana-de-açúcar, a possibilidade de auferir remuneração por desempenho na colheita superior ao salário mínimo faz com que os trabalhadores se desloquem e tolerem a jornada exaustiva, voltando a se submeter ao trabalho escravo, pois a remuneração justifica tudo isso (Phillips \& Sakamoto, 2011).

\section{TABELA 1. Casos identificados de trabalho escravo por atividade (Brasil - de 2011 a 2013)}

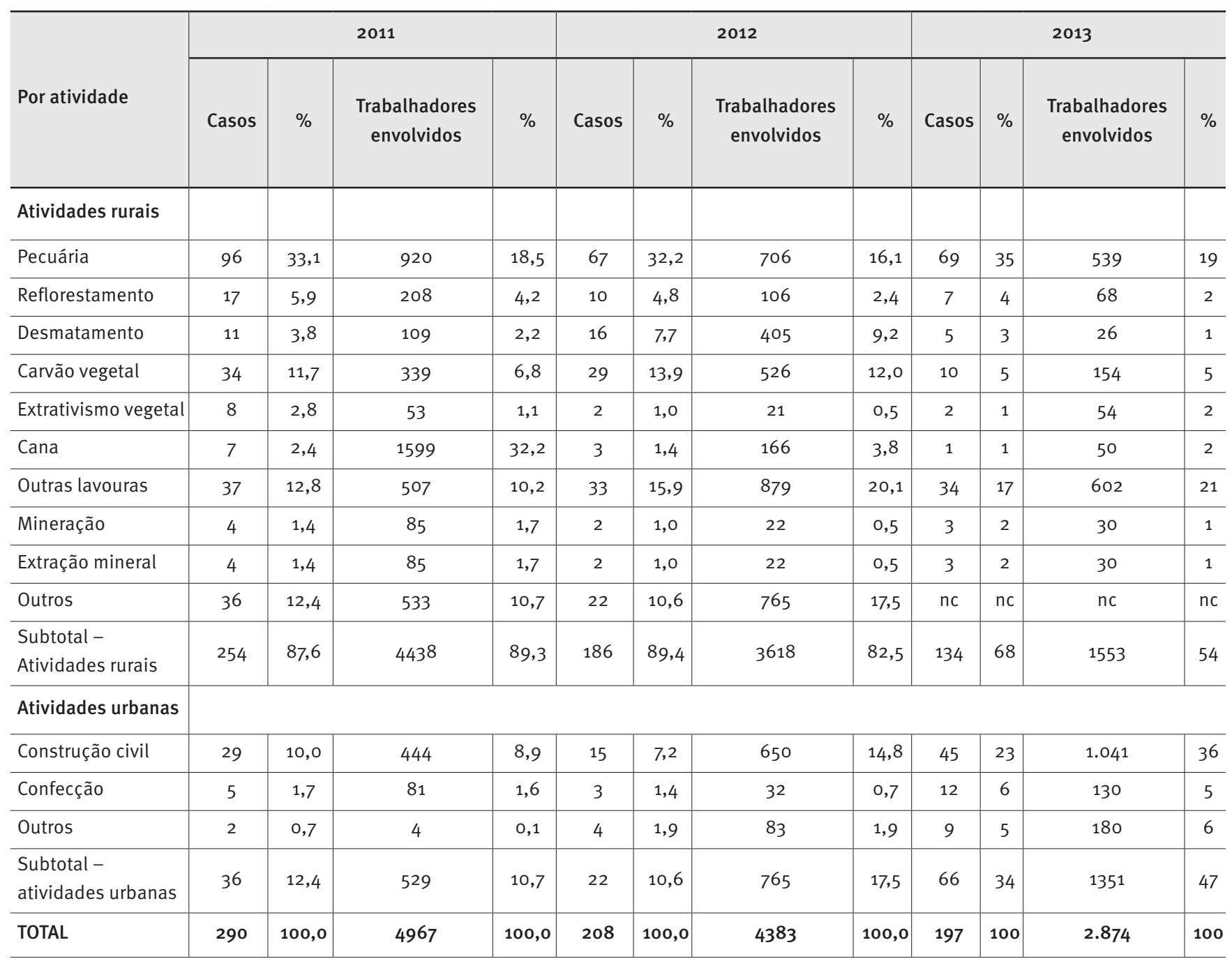


Quanto à segunda proposição, o contexto brasileiro corrobora a afirmação de Crane (2013) de que a exploração do trabalho escravo acontece diante da disponibilidade de grupos em situação de vulnerabilidade social, com alto desemprego, pobreza e baixo nível de escolaridade. No Brasil, o Maranhão tem alguns dos piores indicadores de desenvolvimento e é o principal estado de origem dos escravos. Apesar da pujança da capital São Paulo, no setor de confecções, há alta incidência de casos de trabalho escravo entre imigrantes da Bolívia, país cujos índices de desenvolvimento estão entre os piores da América Latina. Na Amazônia, os processos de concentração de terras e colonização são a base da expansão da agropecuária e vêm induzindo a formação de um mercado de trabalho pela população local vulnerável, muitas vezes, desalojada, a quem pouca alternativa resta além da sujeição à condição análoga à de escravo junto às empresas, médias e grandes, que atuam na região, abastecendo mercados no Brasil e exterior (Phillips \& Sakamoto, 2011). A Tabela 2 mostra comparativo de casos identificados nos anos 2012 e 2013 por região. Nota-se que é na região Norte onde prevalece o maior número de casos e trabalhadores envolvidos.

\section{TABELA 2. Casos de trabalho escravo identificados no Brasil, distribuídos por região}

\begin{tabular}{l|c|c|c|c|c|c}
\hline Trabalho escravo & \multicolumn{2}{|c|}{ Casos identificados } & \multicolumn{2}{c|}{ Trabalhadores envolvidos } & \multicolumn{2}{c}{ Trabalhadores resgatados } \\
\hline Ano & 2012 & 2013 & 2012 & 2013 & 2012 & 2013 \\
\hline Norte & 88 & 55 & 1.824 & 505 & 274 \\
\hline Nordeste & 31 & 42 & 530 & 603 & 371 & 330 \\
\hline Centro-Oeste & 31 & 31 & 346 & 430 & 325 & 623 \\
\hline Sudeste & 21 & 53 & 623 & 1.186 & 309 \\
\hline Sul & 18 & 16 & 357 & 150 & 357 & 147 \\
\hline Total & 189 & 197 & 3.680 & 2.874 & 2.730 & 2.208 \\
\hline
\end{tabular}

Fonte: Procuradoria-Geral da União (2014)

O acesso a programas de inclusão social moderaria a segunda proposição ao alterar, num primeiro momento, a equação risco versus oportunidade daqueles que são alvo dos escravagistas. No Brasil, a falta ou ineficácia de políticas e programas sociais poderia ser associada a altos índices de resgatados que são escravizados novamente. Para combater esse problema, em 2005, por acordo entre o Ministério do Desenvolvimento Social (MDS) e o MTE, o trabalhador resgatado teve prioridade para receber o Bolsa-Família (MTE, 2009). Contudo, diferente da proposição 2a de Crane (2013), estudos mostram que o crédito ou o benefício financeiro não seriam suficientes para desenvolver o capital humano e o capital social, o que demandaria alternativas de trabalho e renda, acesso a programas de capacitação, cidadania e economia solidária, que impulsionariam as economias em desenvolvimento (Ansari, Munir, \& Gregg, 2012; Bradley, McMullen, Artz, \& Simiyu, 2012; Hall, Matos, Sheehan, \& Silvestre, 2012; Khavul \& Bruton, 2013; Senna, Burlandy, Monnerat, Schottz, \& Magalhães, 2007). O Brasil tem articulado políticas públicas, por meio do Ministério do Desenvolvimento Agrário, do Incra e do MTE, e da Secretaria Nacional de Economia Solidária (Senaes), incluindo experiências de microcrédito, moeda social e bancos comunitários, em ações voltadas a agri- cultores familiares, artesãos, trabalhadores autônomos, desempregados e catadores de material reciclável (Senaes, 2013). Referente à terceira proposição, o contexto brasileiro corrobora a afirmação de Crane (2013) de que a prática da escravidão se beneficia da existência de condições de isolamento geográfico do empreendimento e vulnerabilidade social, psicológica, política e física dos trabalhadores, o que diminui os custos e riscos da coerção. Na modalidade contrato de escravidão, uma rede de intermediários faz promessas ao trabalhador, que percebe somente no local de trabalho que o acordo não será cumprido. É comum o trabalhador ser cerceado de sua liberdade por métodos violentos e obrigado a pagar dívida fabricada, impedindo o acesso ao salário acordado (Bales, 2004; Figueira, 2004; Sharma, 2008; Silva, 2004).

Na cadeia de produção pecuária brasileira, por exemplo, o aliciamento de trabalhadores por "gatos" é feito por meio da promessa de boa renda, muitas vezes mediante um adiantamento que constitui alívio financeiro à família. Os trabalhadores já estão isolados no longínquo local de trabalho quando percebem que o que lhes fora prometido não será necessariamente cumprido. Impotente diante do empregador e frequentemente imbuído da responsabilidade diante da oportunidade, o trabalhador 
é facilmente explorado, não raro sob ameaça armada, moral ou psicológica, e não abandona o local de trabalho (Figueira, 2004; OIT, 2003; Silva, 2004). No caso do Brasil, muitas vezes o trabalhador encontra-se preso à atividade laboral por esquemas geográficos, vigilância, confinamento, ameaça de morte e de denúncia à polícia local da situação imigratória irregular.

Quanto à quarta proposição, o contexto brasileiro corrobora a afirmação de Crane (2013) de que um contexto cultural que reforça desigualdades e naturaliza relações de trabalho coercitivas beneficia a prática da escravidão. De fato, a história das relações de trabalho no Brasil revela práticas tradicionais com significados regionais, que comumente guardavam uma índole violenta e opressiva, como o cativeiro, o colonato e o sistema de aviamento ou morada (Figueira, 2004; Prado, 1967). No Brasil, uma análise sugere que, nas regiões onde há trabalho escravo, o processo produtivo marcado pelo crime tipificado no artigo 149 é considerado natural ou aceitável. A vinda do auditor e do procurador do MTE seria um tipo de endocolonialismo, pois eles não convivem com a realidade da pecuária e do extrativismo (Cazetta, 2007). Entende-se que a escravidão manifesta-se como reprodução de estruturas de dominação, culturalmente aceitas, já que muitos empresários, fazendeiros, parlamentares, magistrados, políticos, advogados e peões consideram normal, ou tradicional, esse padrão de relação de trabalho, que seria, inclusive, compatível com as ambições agroexportadoras do País (Plassat, 2008).

Na quinta proposição, o contexto brasileiro corrobora a afirmação de Crane (2013) de que a regulação pública ou privada tem um efeito moderador sobre a exploração da mão de obra escrava. Quanto à eficiência do contexto regulatório, o caso brasileiro revela a articulação entre atores públicos e privados em torno do reconhecimento do problema e da construção de mecanismos de punição do crime e de uma matriz de políticas públicas, abrangendo transferência de renda, reforma agrária e combate à fome. No Brasil, o ciclo da política pública para erradicação do trabalho escravo coincide com um processo de priorização e aumento da atenção e da governança diante do problema, em nível societal, quando foram criadas esferas de debate público e instrumentos legais de enquadramento, repressão e punição, além de um plano executivo de metas.

Apesar de o Brasil ter adotado as convenções internacionais que baniam as práticas do trabalho escravo e do trabalho forçado, foi somente após o fim do regime militar que denúncias referentes a práticas coercitivas de trabalho passaram a ecoar junto a formuladores de políticas públicas. Esse processo iniciou-se efetivamente em 1970, pelas mãos de padres, freiras, aliados da Igreja Católica, advogados, jornalistas e políticos opositores. A partir dos anos 1980, com o movimento de rede- mocratização, organismos da sociedade civil articularam-se em um movimento de denúncias que acabaria culminando no reconhecimento do problema perante a OIT, em 1995, o que levou à criação do Grupo Especial de Fiscalização Móvel (GEFM), que atuava segundo uma estratégia de autuação mediante denúncia. Em 2004, o Brasil se comprometeu perante a ONU a implantar uma política de erradicação (Villela, 2008).

Ao longo das décadas de 1990 e 2000 , foram criadas e aperfeiçoadas as esferas de debate público, instrumentos legais e de enquadramento, repressão e punição (Instituto Socioambiental [ISA], 2008). Na sociedade civil, fortaleceram-se as redes que vêm lutando pela erradicação da escravidão. Na esfera jurídica, em 2003, foi dada uma nova redação ao artigo 149 do Código Penal pela Lei n. 10.803, que se tornou o instrumento jurídico para o enquadramento das práticas degradantes de trabalho utilizadas por empreendimentos. 0 texto gera reclamações, sob o argumento de que o Brasil se afastou do conceito da OIT, que define somente o trabalho forçado. Por outro lado, considera-se avançada a legislação brasileira, que reconhece o trabalho análogo à escravidão mesmo quando não há consciência dessa condição.

Na esfera legislativa, a Proposta de Emenda Constitucional (PEC) n. 438 propõe a expropriação das terras flagradas na exploração do trabalho em condições análogas à de escravo, destinando-as à reforma agrária (MTE, 2011b). Sua proposição, em 1999, pôs em evidência o debate em torno do conceito de trabalho escravo. Entre as próximas questões de regulação, o Projeto de Lei n. 4.330/2004, que regulamenta a terceirização no Brasil, vem sendo considerado um retrocesso, pois propõe liberá-la na atividade-fim, colocando a responsabilidade pelo crime do trabalho escravo e pela violação das leis trabalhistas sobre o empreiteiro, tirando-a do empregador principal.

No caso brasileiro, estratégia para o combate ao trabaIho escravo tem sido a criação de instrumentos para fortalecer a governança e a institucionalização do problema tanto na esfera pública como na privada. No âmbito da regulação pública, um marco no processo foi a criação do Plano Nacional de Erradicação do Trabalho Escravo, em 2003, formulado pela então criada Comissão Especial do Conselho de Defesa dos Direitos da Pessoa Humana, vinculada à Presidência da República. A Comissão Nacional para a Erradicação do Trabalho Escravo (Conatrae) é um órgão colegiado criado para monitorar a execução do plano, que reunia 76 medidas em uma estratégia em rede, articulado pelos órgãos dos três poderes (Legislativo, Judiciário e Executivo) envolvendo governo e sociedade civil, incluindo ONGs, representantes dos trabalhadores e das empresas (MTE, 2011a; Secretaria Especial dos Direitos Humanos [SEDH], 2008). Com o plano, a erradicação do trabalho escravo mantém-se na agenda 
da Presidência da República, trabalhando com a SEDH e com organismos internacionais como a OIT e o Programa das Nações Unidas para o Desenvolvimento (PNUD). Desde 2003, foram resgatados mais de 44 mil trabalhadores, o que levou a OIT a reconhecer os progressos alcançados.

Mecanismo importante tem sido a "lista suja" do MTE, que designa o cadastro dos empregadores flagrados e condenados administrativamente pela exploração do trabalho em condições análogas à escravidão. A lista torna público o nome das empresas criminosas, identifica-as e informa ministérios e outros órgãos, permitindo bloquear a avaliação e concessão de crédito. A lista suja é a ferramenta mais temida pelos infratores, devido ao monitoramento pela auditoria trabalhista e ao bloqueio de investimentos e financiamentos públicos em setores altamente dependentes do Estado (MTE, 2011b). No início de 2015, o cadastro reunia um número de 575 empregadores em situação ilegal (Repórter Brasil, 2015).

As redes da sociedade civil têm sido determinantes para alcançar a opinião pública, articular soluções e construir conhecimento e consciência sobre o problema. No Brasil, ONGs vêm realizando estudos, como mapeamentos de cadeias produtivas, identificando seus elos desde o pequeno produtor aos grandes varejistas, e os custos impostos aos trabalhadores afetados (Greenpeace, 2009; Phillips \& Sakamoto, 2011). Essas iniciativas resultaram no lançamento de relatórios importantes com conteúdo de denúncia e campanhas de conscientização, com repercussão na mídia nacional e internacional.

Na esfera da regulação privada e colaboração na sociedade civil, a ONG Repórter Brasil, o Instituto Ethos, a OIT e o IOS propuseram, em 2005, o Pacto Nacional pela Erradicação do Trabalho Escravo. O pacto é citado pela OIT como referência por integrar empresas signatárias envolvidas em atividades vulneráveis ao trabalho escravo em torno da construção de responsabilidade pelo monitoramento e garantia do respeito aos direitos humanos ao longo de sua cadeia produtiva (IOS, 2011). As empresas comprometem-se a não manter relações comerciais com as que constam na lista suja. 0 pacto reunia, em 2012, 185 signatárias, brasileiras e multinacionais, além de associações comerciais e entidades da sociedade civil que, juntas, contribuem com mais de $20 \%$ do PIB nacional.

O processo de construção da agenda da erradicação do trabalho escravo beneficiou-se também da atenção de setores da mídia, que contribuem ao colocar o problema na agenda pública. Entre os casos de maior repercussão, na indústria têxtil, as Lojas Marisa, Lojas Pernambucanas e a espanhola Zara foram implicadas em casos de trabalhadores escravizados na capital e no interior de São Paulo, a maioria imigrantes bolivianos. $\mathrm{Na}$ construção civil, houve denúncias em construtoras contra- tadas pela estatal Companhia de Desenvolvimento Habitacional e Urbano (CDHU), em São Paulo, e por consórcios responsáveis por grandes obras do Plano de Aceleração do Crescimento (PAC). 0 debate público em torno desses casos inclui a responsabilização pela violação das leis trabalhistas e crime de trabalho escravo ao longo da cadeia produtiva.

\section{DISCUSSÃO E AGENDA DE PESQUISAS}

A problemática da escravidão contemporânea revela aspectos nefastos da globalização da produção e do consumo até agora pouco considerados pelo campo da prática e da pesquisa em Administração de Empresas. 0 caso brasileiro fornece insights importantes, corroborando e ampliando as proposições da teoria da escravidão contemporânea como prática de gestão de Crane (2013).

Em especial, a estratégia de erradicação tem sido caracterizada pelas intervenções e pressões nas cadeias produtivas por meio do enfrentamento do problema com a implementação de mecanismos públicos e privados de regulação. Na agropecuária brasileira, por um lado, os pequenos produtores são inúmeros e estão sujeitos às práticas de compra das empresas processadoras de carne, perseguem a competitividade, mas deterioram as relações de trabalho. Por outro, os mecanismos de política pública, como a lista suja, e de regulação voluntária dos atores da cadeia, como o Pacto Nacional pela Erradicação do Trabalho Escravo, alteram a prevalência de racionalidade econômica na exploração do trabalho escravo. Isso porque a criação da lista suja, as ações de prevenção e a intensificação da fiscalização aumentaram o risco e o custo da inação em empresas dependentes de financiamento do Estado. A ação governamental inclui também um plano executivo de metas e a articulação matricial entre políticas públicas que buscam garantir direitos básicos à população e prevenir o problema.

Persistem, entretanto, contradições no processo, incluindo a ação do próprio governo, que incentiva empresas agropecuárias na franja Amazônica e no Centro-Oeste, enquanto outras forças políticas, de dentro e de fora do governo, buscam alternativas para reduzir seus impactos socioambientais (Repórter Brasil e Papel Social, 2008). As dificuldades para a erradicação do trabalho escravo no Brasil incluem, por um lado, a ineficiência e incapacidade administrativa e técnica na governança pública do problema. Por outro, tentativas de deslegitimação do problema e manutenção do domínio por parte das empresas, fazendas e políticos que buscam reforçar posições tradicionais, incluindo uso de lobbying informal, suborno, ameaças e outras formas de influência e cooptação de políticos e 
funcionários públicos. Assim, embates políticos e judiciais entre os poderes Executivo, Legislativo e Judiciário brasileiros revelam conflitos de interesses entre o governo e a sociedade civil, incluindo empresas do agronegócio, representantes ruralistas (nas esferas estadual e federal) e ONGs. Ainda, aumentou-se a exposição do problema pela mídia e fortaleceram-se as redes da sociedade civil que vêm lutando pela erradicação da escravidão, entre as quais as ONGs, que têm sido determinantes para sensibilizar a opinião pública e construir articulação civil e conhecimento sobre o problema.

A contribuição deste artigo desdobra-se em uma agenda de pesquisa em Administração. Dois aspectos principais justificam essa agenda. Em primeiro lugar, o debate sobre o trabalho escravo contemporâneo acompanha o crescente interesse em compreender os impactos sociais das atividades empresariais para além dos países ricos (Blowfield \& Frynas 2005; Egri \& Ralston 2008; Idemudia 2011). Aqui se resgatam as reflexões de Newell e Frynas (2007), para quem seria desafio central, no campo da Administração, aprofundar e contextualizar o debate para fundamentar estratégias de ação nos países em desenvolvimento, nas quais empresas contribuam com o enfrentamento dos problemas contemporâneos (pobreza, desemprego, educação, meio ambiente, entre outros).

Em segundo lugar, evidencia a discussão do contexto da pobreza e suas inter-relações com o sistema de produção-consumo. (Banerjee, Chio, \& Mir, 2009; Lindsay, 2010; Thornley, Jeffreys, \& Appay, 2010). Apesar do interesse recente na abordagem base da pirâmide (Prahalad, 2006; Ansari e outros 2012) e nas noções de capitalismo inclusivo, o campo não detém a compreensão dos fundamentos da pobreza e sobre como as teorias e práticas da gestão estariam implicadas na sua reprodução e no alívio (Boyle \& Boguslaw, 2007; Jenkins, 2005; Kolk \& Tulder, 2006; Newell \& Frynas 2007; Pehn, 2009; Singer, 2006; Smith, 2009). Na verdade, tais aspectos ficam frequentemente obscurecidos no debate. A prática da responsabilidade social corporativa vem sendo enviesada pelos temas ambientais, em detrimento de visões mais complexas dos problemas a serem enfrentados (Barkemeyer, 2009; Houffman, 2011). Além disso, pobreza vem sendo considerada um tema inconsistente e muito distante do mainstream do business (Khavul \& Bruton, 2013; Principles for Responsible Management Education, 2012). Este artigo sustenta que a problemática da escravidão contemporânea avança nosso conhecimento de como práticas de gestão estariam ligadas à reprodução ou ao aumento da pobreza no mundo (Crane, 2013; Lindsay, 2010; Singer, 2006).

0 artigo sugere também que o objetivo da erradicação do trabalho escravo se beneficiaria da compreensão do contexto e da dinâmica desses processos pelos ângulos da Administra- ção. Segundo uma abordagem institucionalista, por exemplo, a continuidade das discussões em torno da escravidão contemporânea traz consigo o potencial de ampliar a compreensão dos efeitos da globalização nas relações de trabalho em cadeias produtivas. Esses entendimentos seriam fundamentais para a construção de inovações na gestão que contribuam para erradicação do trabalho escravo. Assim, objetivos de uma agenda de pesquisa ampla em Administração incluiriam, por um lado, compreender o trabalho escravo como fenômeno cujos contornos se constroem na microdinâmica de estratégia e gestão das empresas (nível micro), em seus setores e cadeias produtivas (nível meso), nos contextos industriais, socioeconômicos, geográficos e culturais (nível macro).

Por outro lado, essa agenda deve reconhecer a natureza complexa do problema e incorporar os debates das diversas disciplinas que o investigam. Os debates penetram principalmente o campo jurídico (Halley, Kotiswaran, Thomas, \& Shamir, 2006; Lorenzetti, 2010; Monteiro, 2010; Rassam, 2005), direitos humanos (Figueira, Prado, \& Galvão, 2013; Quirk, 2006; Welch, 2009), antropologia, sociologia e estudos de gênero (Doezema, 1999; Meillasooux, 1995) e políticas públicas (Antero, 2008; Lorenzetti, 2010); em estudos de temas como desenvolvimento (Barkemeyer, 2009), pobreza (Boyle \& Boguslaw, 2007; Castilho, 1999; Jenkins, 2005; Khavul \& Bruton, 2013; Kolk \& Tulder, 2006; Pehn, 2009; Phillips \& Sakamoto, 2011; Smith, 2009); segurança e tráfico de pessoas (Clark, 2003; Lobasz, 2009) e crimes corporativos (Oliveira, Valadão, \& Miranda, 2013). As oportunidades que se colocam são diversas, tais como análises-explicativas com aporte teórico de várias correntes, diversificando a reflexão sobre as temáticas que contribuam para entendimento do trabalho escravo como prática de gestão. Entre as abordagens de pesquisa, sugerese investigar:

1. (níveis micro e meso) As capacidades de gestão de pessoas para a erradicação da escravidão e as estratégias para o alívio da pobreza. Apesar de ser controverso o debate sobre a responsabilidade das empresas no alívio da pobreza, o desafio de superá-la é central ao desenvolvimento sustentável e aspecto crucial à expansão dos negócios, principalmente nos países em desenvolvimento. As questões que se colocam incluem: Em que condições as empresas se engajam no alívio à pobreza? Como fazê-lo? Para além dos aspectos de repressão, o campo de estudos em Administração precisa levar a sério a pesquisa e a prática sobre o alívio da pobreza como estratégia de negócios e como compromisso e retribuição à sociedade (Singer, 2006). Segundo Kolk e Tulder (2006), apesar de pouco significativos os esforços de multinacionais 
no alívio à pobreza, um olhar mais aproximado às dinâmicas setoriais revela aspectos que estariam correlacionados ao seu envolvimento nessas questões. Para esses autores, profícuo seria facilitar o diálogo e a ação no nível setorial (meso), e não somente no nível da empresa (micro) ou das nações (macro), como tendem a fazer ONGs e organismos internacionais. No nível da gestão, podemos falar em RH sustentável? Quais são as capacidades de gestão de pessoas requeridas do RH para erradicar a escravidão? Como atua, ou deveria atuar, o RH nas cadeias produtivas com exploração de trabalho escravo? O debate sobre o "RH verde" (Green HR) revela-se demasiadamente centrado na economia verde, questões ambientais e seus desdobramentos em gestão de pessoas (Ehnert, 2009; Jackson, Renwick, Jabbour, \& Muller-Carmen, 2011). Esse viés não reflete a realidade dos países em desenvolvimento, nos quais os desafios são, mais claramente, socioambientais e frequentemente atuando nas margens de cadeias de produção globais (Levy, 2008). A questão da exploração de mão de obra escrava também aponta oportunidades ao debate sobre ética, direitos e dignidade humana no contexto da gestão de pessoas (Greenwood \& Freeman, 2011).

2. (nível meso) As dinâmicas interorganizacionais de poder e política nas cadeias produtivas que exploram o trabalho escravo. Em cadeias de produção complexas, a competição entre as "frações do capital" implica empresas impondo aos elos menos poderosos pressões no que diz respeito a preço, qualidade e logística, acentuando sua rentabilidade, com desdobramentos nas relações de trabalho ao longo da cadeia. Com a organização das cadeias produtivas, o trabalho escravo não seria resquício de modos arcaicos de produção, mas um instrumento de acumulação do capital (Phillips \& Sakamoto, 2011). Sem a exploração dos elos mais fracos da cadeia, empreendimentos rurais em áreas de expansão não teriam a mesma capacidade para concorrer na economia globalizada. A competição entre empreendimentos no interior de cadeias produtivas globais põe os pequenos produtores em desvantagem diante dos elos mais poderosos, seja pelo pouco ou nenhum poder de barganha que lhes faz reféns dos grandes players, ou pelo foco da política pública na fiscalização, que lhes reserva as punições mais severas. Nessa perspectiva de pesquisa, podem-se apontar os avanços recentes no entendimento das redes de produção globais (global production networks) como campos de contestação e colaboração envolvendo empresas, estado e atores sociais, conforme abordagens da nova sociologia econômica (Levy, 2008; Levy \& Newell, 2005).
3. (nível meso e macro) Os aspectos e as dinâmicas dos mercados de trabalho que reforçam a pobreza crônica. A crescente insegurança e precarização do trabalho são associadas à necessidade de flexibilidade e terceirização em nome da competitividade global (Thornley et al, 2010). Em regiões pobres, empresas multinacionais e locais operariam mecanismos coercitivos da globalização, reproduzindo condições históricas de desigualdade (Banerjee et al, 2009; Lichtenstein, 2010; Luxemburgo, 1984). Segundo essa visão, a pobreza não seria eliminada com a expansão dos mercados, pois, em muitos casos, a projeção global das cadeias produtivas fortaleceria empresas locais, mas não permitiria aos trabalhadores ascender socialmente (Barrientos, Gerefei, \& Rossi, 2010). Em vez disso, revelaria formas extremas de exploração do trabalho que perpetuam a vulnerabilidade e a pobreza crônica (Phillips \& Sakamoto, 2011). Seria desejável que a agenda de pesquisa abarcasse os mecanismos pelos quais um amplo espectro de relações de trabaIho reforça a pobreza crônica, buscando a compreensão do que fundamentaria sistemas locais sustentáveis de trabaIho (Docherty, Kira, \& Shani, 2009).

4. (nível macro) As implicações do contexto regulatório público e privado na erradicação do trabalho escravo. Seria necessário aprofundar as contribuições, oportunidades, contradições e desafios do processo de construção e implementação da regulação pública e privada na erradicação do trabalho escravo. Esse debate precisa ser ampliado para capturar as consequências das práticas trabalhistas no atual modelo globalizado e neoliberal de produção e consumo em massa (Boyle \& Boguslaw, 2007; Jenkins, 2005; Kolk \& Tulder, 2006; Newell \& Frynas 2007; Pehn, 2009; Singer, 2006; Smith, 2009). Nesse cenário, enquadra-se o estudo da teoria da implementação de políticas públicas que articulam o cumprimento voluntário, o cumprimento forçado e a dissuasão (Lorenzetti, 2010). Essa agenda pode ser motivada por questões prioritárias: Quais são os limites entre o papel do Estado e das empresas para lidar com a temática? Como as ações de responsabilidade social corporativa podem ajudar a erradicar a pobreza, diminuir a exclusão social e outros desafios do desenvolvimento? Que responsabilidades têm empresas, governos e sociedade civil no enfrentamento dessas questões e em torno das Metas do Milênio das Nações Unidas? Que práticas, estratégias e metodologias podem colaborar para realizar a contribuição potencial das empresas aos desafios do desenvolvimento sustentável (Karam \& Jamali, 2013; Houffman \& Jennings, 2011; Newell \& Frynas, 2007)? Nessa direção, uma agenda de pesquisa mais consistente deve caminhar para incorpo- 
rar os debates de outras áreas do conhecimento, desenvolvendo suas interfaces com a Administração e contribuindo para encaminhamento de soluções.

5. (nível macro) 0 comportamento dos mercados consumidores diante do trabalho escravo. Estudos sobre consumo responsável revelam um ângulo da problemática ao aprofundar a compreensão do comportamento do consumidor diante das informações do processo de erradicação do trabalho escravo. As respostas dos mercados consumidores ao problema do trabalho escravo seriam dimensão importante para entender a reprodução ou a transformação dessas práticas. A consolidação da agenda da erradicação tem chamado a atenção para dimensões sociais insustentáveis de cadeias produtivas lideradas por grandes empresas com reputações sensíveis, como no setor de moda (Veludo-de-Oliveira, Mascarenhas, Trouchin \& Baptista, 2014). Mesmo com maior esclarecimento nos mercados consumidores quanto à realidade das cadeias produtivas, ficaria por discutir como induzir o consumidor a hábitos de consumo responsáveis, o que requer contextualizar o debate sobre o consumo responsável (Creyer, 1997; Carrigan \& Attalla, 2001; Kollmuss \& Agyeman, 2002; McDonagh, 2002; Protero e outros, 2011).

\section{NOTA DOS AUTORES}

Gostaríamos de agradecer aos professores Rafael Alcadipani, Mário Aquino Alves, Patrícia Mendonça e Andrew Crane, à equipe da Repórter Brasil, em especial, Leonardo Sakamoto e Daniel Santini, aos avaliadores e ao editor científico da $R A E$, cujos comentários foram valiosos ao aperfeiçoamento do texto. Os autores também gostariam de agradecer ao CNPq pelo financiamento concedido. Convidamos a visitar e participar do debate em nosso Grupo de Estudos sobre Escravidão Contemporânea e a Administração, em zetesis.net/escravidao-contemporanea-administracao.

\section{REFERÊNCIAS}

Ansari, S, Munir, K, \& Gregg, T. (2012). Impact at the 'bottom of the pyramid': the role of social capital in capability development and community empowerment. Journal of Management Studies, 49(4), 813-842.

Antero, S. (2008). Monitoramento e avaliação do programa de erradicação do trabalho escravo. RAP-Revista de Administração Pública, 42(5), 791-828.

Bales, K. (2004). Disposable people: new slavery in global economy (Vol. 3). Berkeley and Los Angeles: University of California Press.
Bales, K. (2007). Ending slavery. How free today's slaves (Vol. 1). Berkeley: University of California Press.

Bales, K. (2011). Trabalho escravo. Seminário Internacional do Pacto Nacional pela Erradicação do Trabalho Escravo, Brasília, 4.

Bales, K, \& Robbins, P. T. (2001). No one shall be held in slavery or servitude: a critical analysis of international slavery conventions. Human Rights Review, 2(2), 18-45.

Bales, K, Trodd, Z, \& Williamson, A. K. (2009). Modern slavery: the secret world of 27 million people (Vol. 1). London: Oneworld Oxford.

Banerjee, S, Chio, V, \& Mir, R. (2009). The imperial formations of globalization. In S. Banerjee, V. Chio, \& R. Mir (Eds.). Organizations, markets and imperial formations: towards an anthropology of globalization. Cheltenham: [s.n.].

Barkemeyer, R. (2009). Beyond compliance - below expectations? Cross-border CSR, development and the UN Global Compact. Business EthiCS: A European Review, 18(3), 273-289.

Barrientos, S, Gerefei, G, \& Rossi, A. (2010). Economic and social upgrading in global production networks: developing a framework for analysis [Working Paper n. 3]. Capturing the Gains. Manchester, UK.

Bartley, T. (2007). Institutional Emergence in an Era of Globalization: the rise of transnational private regulation of labor and environmental conditions. American Journal of Sociology, 113(2), 297-351.

Blowfield, M, \& Frynas, J. G. (2005). Setting new agendas: critical perspectives on corporate social responsibility in the developing world. International Affairs, 81(3), 499-513.

Boyle, M, \& Boguslaw, J. (2007). Business, poverty and corporate citizenship. Journal of Corporate Citizenship, 20(26), 101-120.

Bradley, S. W., McMullen, J. S., Artz, K., \& Simiyu, E. M. (2012). Capital is not enough: innovation in developing economies. Journal of Management Studies, 49(13), 684-717.

Breton, B. Le. (2002). Vidas roubadas. A escravidão moderna na Amazônia brasileira (Vol. 2). São Paulo: Loyola.

Carrigan, M, \& Attalla, A. (2001). The myth of the ethical consumer do ethics matter in purchase behavior? Journal of Consumer Marketing, 18(7), 560-578.

Cashore, B. (2002). Legitimacy and the privatization of environmental. International Journal of Policy, Administration and Institution, 15(4), 503-529.

Castilho, E. W. (1999). Em busca de uma definição jurídico-penal de trabalho escravo. In Comissão Pastoral da Terra (Org.). Trabalho escravo no Brasil contemporâneo (Vol. 1). São Paulo: Loyola.

Cazetta, U. (2007). A escravidão ainda resiste. Encontro dos Agentes Públicos Responsáveis pelo Combate ao Trabalho Escravo, Ministério Público do Trabalho, Brasília, 1.

Clark, B. (2003). Trafficking in persons: an issue of human security. Journal of Human Development, 4(2), 247-263.

Cooke, B. (2003). The denial of slavery in management studies. Journal of Management Studies, 40(8), 1895-1918.

Crane, A. (2013). Modern slavery as a management practice: exploring the conditions and capabilities for human exploitation. Academy of Management Review, 38(1), 53.

Crane, A, \& Matten, D. (2010). Business ethics: managing corporate citizenship and sustainability in an age of globalization (Vol. 3). Oxford: Oxford University Press. 
Creyer, E. (1997). The influence of firm behavior on purchase intention: do consumers really care about business ethics? Journal of Consumer Marketing, 14(6), 421-432.

Docherty, P, Kira, M, \& Shani, A. B. (2009). Creating sustainable work systems. Abingdon: Routledge.

Doezema J. (1999). Loose women or lost women? The re-emergence of the myth of 'white slavery' in contemporary discourses of trafficking in women. Gender Issues, 18(1), 23-50.

Egri, C. P, \& Ralston, D. A. (2008). Corporate responsibility: a review of international management research from 1998 to 2007. Journal of International Management, 14(4). 319-339

Ehnert, I. (2009). Sustainable human resource management. A conceptual and exploratory analysis from a paradox perspective (Vol. 1). Heidelberg: Springer.

Figueira, R. R. (2004). Pisando fora da própria sombra: a escravidão por dívida no Brasil contemporâneo (Vol. 1). Rio de Janeiro: Civilização Brasileira.

Figueira, R. R, Prado, A. A, \& Galvão, E. M. (2013). Privação de liberdade ou atentado à dignidade: escravidão contemporânea (Vol. 1). Rio de Janeiro: Maud X.

Greenpeace (2009). A farra do boi na Amazônia. São Paulo: Escritório do Greenpeace.

Greenwood, M, \& Freeman, R. E. (2011). Ethics and HRM: the contribution of stakeholder theory. Business \& professional. Ethics Journal, 30, 3-4.

Hall, J., Matos, S., Sheehan, L. \& Silvestre, B. (2012). Entrepreneurship and innovation at the base of the pyramid: a recipe for inclusive growth or social exclusion? Journal of Management Studies, 49(14), 785-812.

Halley, J. E., Kotiswaran, P., Thomas, C. \& Shamir, H. (2006). From the international to the local in feminist legal responses to rape, prostitution/sex work and sex trafficking: four studies in contemporary governance feminism. Harvard Journal of Law \& Gender, 29(2), 335-398.

Houffman, A. J. (2011). The BP Oil spill as a cultural anomaly? Institutional context, conflict, and change. Journal of Management Inquiry, 24(1), 3-33.

Idemudia, U. (2011). Corporate social responsibility and developing countries moving the critical CSR research agenda in Africa forward. Progress in Development Studies, 11(1), 1-18.

Instituto Observatório Social. (2004). Trabalho escravo no Brasil. O drama dos carvoeiros, a responsabilidade das siderurgias, a campanha para erradicação. São Paulo: Instituto Observatório Social.

Instituto Observatório Social. (2011). Erradicação do trabalho escravo é discutida em seminário, em Brasília. Seminário Internacional do Pacto Nacional pela Erradicação do Trabalho Escravo. MTE, Brasília, 4. Recuperado em 05 de maio de 2012 de http://portal.mte.gov. br/imprensa/erradicacao-do-trabalho-escravo-e-discutida-emseminario-em-brasilia.htm

Instituto Socioambiental. (2008). Almanaque Brasil Socioambiental. São Paulo: Instituto Socioambiental.

Jackson, S., Renwick, D., Jabbour, C. \& Muller-Camen M. (2011). State-o$\mathrm{f}$-the-art and future directions for green human resource management: introduction to the special issue. Zeitschrift für Personalforschung, 25(2), 99-116.

Jenkins, R. (2005). Globalization, corporate social responsibility and poverty. International Affairs, 81(3) 525-540.
Karam, C. M, \& Jamali, D. (2013, January). Gendering CSR in the Arab Middle East. An institutional perspective. Business Ethics Quarterly, 23(1), 31-68.

Khavul, S, \& Bruton, G. D. (2013). Harnessing innovation for change: sustainability and poverty in developing countries. Journal of Management Studies, 50, 285-306.

Kolk, A, \& Tulder, R. (2006). Poverty alleviation as business strategy? Evaluating commitments of frontrunner multinational corporations. World Development, 34(5), 789-801.

Kollmuss, A, \& Agyeman, J. (2002). Mind the gap: why do people act environmentally and what are the barriers to pro-environmental behavior? Environmental Education Research, 8(3), 239-260.

Levy, D. (2008). Political contestation in global production networks. Academy of Management Review, 33(4), 943-963.

Levy, D. L, \& Newell, P. A. (2005). Neo-Gramscian approach to business in international environmental politics: an interdisciplinary, multilevel framework. In D. L. Levy, \& P. Newell (Eds.). The business of global environmental governance (pp. 47-69). Cambridge: MIT Press.

Lichtenstein, N. (2010). In the age of Wal-Mart: precarious work and authoritarian management in the global supply chain. In C. Thornley, S. Jeffreys, \& B. Appay (Eds.). Globalization and precarious forms of production and employment. Challenges for workers and unions (pp. 23-40). Cheltenham: [s.n.].

Lindsay, D. M. (2010). Organizational liminality and interstitial creativity: the fellowship of power (Vol. 89). London: [s.n.].

Lobasz, J. K. (2009). Beyond border security: feminist approaches to human trafficking. Security Studies, 18(2), 319-344.

Lorenzetti, R. L. (2010). Teoria geral do direito ambiental. São Paulo: Revista dos Tribunais.

Luxemburgo, R. (1984). A acumulação do capital: contribuição ao estudo econômico do Imperialismo (Vols. 1 e 2). São Paulo: Abril Cultural.

McDonagh, P. (2002). Communicative campaigns to effect anti-slavery and fair trade: the cases of Rugmark and Cafédirect. European Journal of Marketing, 36(5-6), 642-666.

Meillassoux, C. (1995). Antropologia da escravidão: o ventre de ferro e dinheiro (Vol. 1). Rio de Janeiro: Jorge Zahar.

Ministério do Trabalho e Emprego. (2009). Perguntas e respostas sobre trabalho análogo ao de escravo no Brasil. Já fizemos muito e estamos trabalhando por mais. Brasília: MTE.

Ministério do Trabalho e Emprego. (2011a). Manual de combate ao trabalho em condições análogas às de escravo. Brasília: Ministério do Trabalho e Emprego.

Ministério do Trabalho e Emprego. (2011b). Erradicação do trabalho escravo é discutida em seminário, em Brasília. Seminário Internacional do Pacto Nacional pela Erradicação do Trabalho Escravo, MTE, Brasília, 4. Recuperado em 05 de maio de 2012 de http://portal.mte.gov.br/ imprensa/erradicacao-do-trabalho-escravo-e-discutida-em-seminarioem-brasilia.htm

Monteiro, J. C. (2010). Trabalho decente: análise jurídica da exploração, trabalho escravo e outras formas de trabalho digno (Vol. 1). São Paulo: LTr.

Newell, P, \& Frynas, J. G. (2007). Beyond CSR? Business, poverty and social justice: an introduction. Third World Quarterly, 28(4), 669-681.

Oliveira, C. R, Valadão, V. M, Jr, \& Miranda, R. (2013). Culpada ou inocente? Comentários de internautas sobre crimes corporativos. RAERevista de Administração de Empresas, 53(6), 617-628. 
Organização Internacional do Trabalho. (2003). Trabalho escravo no Brasil. OIT, Genebra, 21.

Organização Internacional do Trabalho. (2004). Uma aliança global contra o trabalho escravo: relatório global do seguimento da declaração da OIT sobre os princípios e direitos fundamentais no trabalho. Genebra: OIT.

Organização Internacional do Trabalho. (2009). O custo da coerção: relatório global no seguimento da Declaração da ILO sobre os direitos e princípios fundamentais do trabalho. Genebra: OIT.

Organização Internacional do Trabalho. (2011). Combate ao trabalho forçado: manual para empregadores e empresas. Brasília: OIT.

Penh, B. (2009, March). New convergences in poverty reduction, conflict, and state fragility: what business should know. Journal of Business Ethics, 89(4), 515-528.

Phillips, N, \& Sakamoto, L. (2011). The dynamics of adverse incorporation in global production networks: poverty, vulnerability and 'slave labour' in Brazil. Chronic Poverty Research Center, 175(1), 1-47.

Plassat, X. (2008). Abolida a escravidão? In G. C. de Cerqueira, R. R. Figueira, A. A. Prado, \& C. M. L. Costa. (Orgs.) Trabalho escravo contemporâneo no Brasil: contribuições críticas para sua análise $e$ denúncia (Vol. 1, pp. 73-95). Rio de Janeiro: UFRJ.

Prado, C, Jr. (1967). A formação do Brasil contemporâneo (Vol. 10). São Paulo: Companhia das Letras.

Prahalad, C. K. (2006). A riqueza na base da pirâmide. Porto Alegre: Bookman.

Principles for Responsible Management Education. (2012). Fighting poverty through management education: challenges, opportunities, solutions. Relatório preparado ao PRME Global Forum, Rio de Janeiro, 3.

Procuradoria-Geral Da União. (2014). Eco Debate. Recuperado em 20 janeiro, 2014, de http://www.ecodebate.com.br/2014/01/29/mpfapresenta-dados-do-combate-ao-trabalho-escravo-no-brasil/

Prothero, A., Dobscha, S., Freund, J., Kilbourne, W., Luchs, M., Ozanne, L. \& Thøgersen, J. (2011). Sustainable consumption: opportunities for consumer research and public policy. Journal of Public Policy \& Marketing, 30(1), 31-38.

Quirk, J. (2006). The anti-slavery project: linking the historical and contemporary. Human Rights Quarterly, 28(3), 565-598.

Rassam, A. Y. (2005). International law and contemporaneous forms of slavery: an economic and social rights-based approuch. Carlisle: Spring.

Repórter Brasil e Papel Social. (2008). Conexões sustentáveis São Paulo - Amazônia. Quem se beneficia com a destruição da Amazônia. São Paulo: ONG Repórter Brasil.

Repórter Brasil (2015). Lista suja do trabalho escravo. Recuperado em 28 de janeiro de 2015 de http://reporterbrasil.org.br/listasuja/resultado.php

Sakamoto, L. (2008). A economia do trabalho escravo no Brasil contemporâneo. In G. C. de Cerqueira, R. R. Figueira, A. A. Prado, \& C. M. L. Costa. (Orgs.) Trabalho escravo contemporâneo no Brasil: contribuições críticas para sua análise e denúncia (Vol. 1, pp. 61-71). Rio de Janeiro: Editora UFRJ.
Secretaria Especial dos Direitos Humanos. (2008). Plano Nacional para Erradicação do Trabalho Escravo. Presidência da República, Secretaria Especial dos Direitos Humanos, Brasília, 2.

Sistema Nacional de Economia Solidária. (2013). Acontece Senaes. Divulgação dos dados. Brasília: SENAES.

Senna, M., Burlandy, L., Monnerat, G., Shottz, V., \& Magalhães, R. (2007). Programa Bolsa Família: nova institucionalidade no campo da política social brasileira? Revista Katálysis, 10(1), 86-94.

Sharma, B. (2008). Anti-Slavery International e o combate ao trabalho escravo. In G. C. de Cerqueira, R. R. Figueira, A. A. Prado, \& C. M. L. Costa. (Orgs.) Trabalho escravo contemporâneo no Brasil: contribuições críticas para a sua análise e denúncia (Vol. 1, pp. 39-46). Rio de Janeiro: UFRJ.

Silva, F. A. D. (2004). Os grilhões da escravidão no Brasil contemporâneo e a proteção legal do trabalhador rural (Vol. 1). Tese de doutorado, Direito, Pontíficia Universidade Católica de São Paulo, São Paulo.

Singer, A. (2006). Business strategy and poverty alleviation. Journal of Business Ethics, 66(2-3), 225.

Smith, B. (2009). Annotated bibliography on social exclusion, adverse incorporation and chronic poverty. Chronic Poverty Research Center, $86,1-20$.

Thornley, C, Jefferys, S, \& Appay, B. (2010). Globalization and precarious forms of production and employment. Challenges for workers and unions. London: London Metropolitan University.

Valente, M, \& Crane, A. (2010). Private enterprise and public responsibility in developing countries. California Management Review, 52(3), 52-78.

Veludo-de-Oliveira, T, Mascarenhas, A, Tronchin, G, Baptista, R. (2014). Consumo socialmente responsável no varejo da moda: Analisando a intenção dos consumidores de deixar de comprar de empresas denunciadas por escravidão contemporânea. RGSA-Revista de Gestão Social e Ambiental, 8(2), 63-75.

Viana, M. T. (2007). Trabalho escravo e "lista suja": um modo original de se remover uma mancha. Brasília: Organização Internacional do Trabalho.

Villela, R. (2008). O Grupo Especial de Fiscalização Móvel. In G. C. de Cerqueira, R. R. Figueira, A. A. Prado, \& C. M. L. Costa. (Orgs.). Trabalho escravo contemporâneo no Brasil: contribuições críticas para a sua análise e denúncia (Vol. 1, pp. 141-156). Rio de Janeiro: UFRJ.

Welch, C. E. (2009). Defining contemporary forms of slavery: updating a venerable NGO. Human Rights Quarterly, 31(1), 70-128.

Zocchio, G. (2013). Quase 3 mil foram resgatados do trabalho escravo, São Paulo: ONG Repórter Brasil. Recuperado em 2 outubro, 2013, de http://reporterbrasil.org.br/2013/05/quase-3-mil-foram-resgatados-do-trabalho-escravo-em-2012/ 